\title{
A scoping review of non-communicable diseases and maternal and child health needs of Venezuelan migrants in South America
}

\author{
Benjamin Gallo Marin ${ }^{1}{ }^{a}$, Andres Amaya ${ }^{\text {b }}$, Giancarlo Medina Perez ${ }^{1}$, Adam C. Levine ${ }^{2}$, Katelyn Moretti ${ }^{2}$, \\ Stephanie C. Garbern ${ }^{2}$ \\ 1 Warren Alpert Medical School of Brown University, Providence, Rhode Island, United States, 2 Department of Emergency Medicine, Warren Alpert \\ Medical School of Brown University, Providence, Rhode Island, United States \\ Keywords: humanitarian, global health, migrant health, venezuela \\ https://doi.org/10.29392/001c.23621
}

\section{Journal of Global Health Reports}

Vol. 5, 2021

\begin{abstract}
Background
Migration of Venezuelan citizens to other South American countries has increased in recent years. While the prevalence, morbidity, and mortality of infectious diseases in Venezuelan migrants across South America appears to be well described, the non-communicable disease (NCD) and maternal and child health needs in this population is less clear. A scoping review of existing peer-reviewed primary research and grey literature describing the epidemiology of NCDs and maternal and child health needs in Venezuelan migrants in major South American host countries was performed in order to highlight important gaps in knowledge.
\end{abstract}

\section{Methods}

A scoping review was performed of peer-reviewed research and grey literature for NCD and maternal and child health needs among Venezuelan migrants living in the following host South American countries with greater than 100,000 migrants: Argentina, Brazil, Chile, Colombia, Ecuador, and Peru. A total of 47 electronic databases were searched for primary research published between 2017 and 2020 in either English or Spanish.

\section{Results \\ Out of 1,098 initial articles retrieved, 17 records met inclusion criteria, with the majority identified from the grey literature. Most studies were published in 2019 and most were either primary reports published by non-governmental organizations within the grey literature search or cross-sectional qualitative studies. Studies came from Argentina, Chile, Colombia, and Peru, with three records offering a regional perspective. Most studies provided broad data on NCDs and maternal and child health needs but lacked granular statistics. Our analysis found the rate of chronic disease among Venezuelan migrants to range from $9-14 \%$ within countries who reported this data. Significant rates of psychiatric conditions such as depression and post-traumatic stress disorder were reported. Other conditions described were ophthalmologic diseases, diabetes, chronic pain, asthma, cough, dyslipidemia, hypertension, arthritis, malnutrition, and obstetric complications, although exact statistics were limited. Obstacles to care included lack of healthcare access and affordability.}

\section{Conclusions}

Existing reports discuss important needs related to NCDs and maternal and child health in Venezuelan migrants in South American countries, but there are significant gaps in knowledge. Further research must describe in greater detail the prevalence, morbidity, and mortality of NCDs and maternal and child health needs in Venezuelan migrants in

\footnotetext{
a Equal authorship

b Equal authorship

c Equal authorship

d Equal authorship
} 
this region in order to assist local governments and international humanitarian organizations with providing strategic and unified responses.

Since 2015, over five million Venezuelans have left their home country due to an ongoing political, economic, and humanitarian crisis. ${ }^{1}$ More than four million of these people have relocated to other countries in Latin America. ${ }^{2}$ The large influx of Venezuelans into other Latin American countries represents an important stressor to healthcare systems across the region with potential associated epidemiologic shifts in disease burdens for host countries. However, the health implications of these migratory processes in South America remain unclear. Understanding the health needs of the Venezuelan migrant population that has relocated to other South American countries is necessary in order to provide a logical and unified response that meets international humanitarian standards.

Often, the first step in understanding a migrant population's health care needs is to examine the baseline prevalence of disease in their home countries. ${ }^{3}$ In Venezuela, years of declining preventive health services, public health and disease surveillance, weakening of academic medical institutions, shortages of healthcare professionals, economic turbulence, and political oppression have contributed to the crumbling of the Venezuelan healthcare system. ${ }^{4-6}$ Decreased availability of key healthcare resources, including essential medications and diagnostic services have been documented. ${ }^{7-11}$ For example, the Pharmaceutical Federation of Venezuela estimated in 2018 that the country was suffering from an $85 \%$ shortage of medicine brands and reports from healthcare workers to Humans Right Watch state that lack of medicines and resources complicates the delivery of proper care. ${ }^{12,13}$

After suppressing general public health data for at least two years, in 2017 the Venezuelan Ministry of Health released several alarming healthcare outcome statistics which clarified the difficult situation facing the country. ${ }^{14}$ For example, from 2008 to 2019, a 40\% increase in the child mortality rate was documented, reversing a downward trend that began in the late 1990's. ${ }^{9,15-18}$ Severe food shortages were linked to high rates of malnutrition, which have in turn been linked to worse health outcomes. ${ }^{7,9,16}$ In 2018, the UN's Food and Agriculture Organization (FAO) estimated that between 2015 and 2017, approximately 3.7 million people - representing $11.7 \%$ of the Venezuelan population - were undernourished, compared to less than 5\% between 2008 and 2013. ${ }^{19}$

Most published data about the status of Venezuelan migrant health has related to the infectious disease burden, where an increase in the incidence of previously controlled illnesses including Zika, chikungunya, Chagas disease, measles, and diphtheria have been reported. ${ }^{17,20-23}$ However, the impact on non-communicable diseases (NCDs) and maternal and child health is less clear. Globally, NCDs accounted for over 38 million deaths (62\%) in 2012 with $80 \%$ occurring in low- and middle-income countries. Despite efforts by the WHO to increase NCD monitoring prevention and treatment, countries continue to struggle with the NCD epidemic. ${ }^{24}$

A lack of trust regarding the transparency of government-provided data has resulted in a poor understanding of the true epidemiological picture of the Venezuelan population as a whole. ${ }^{25}$ Instead, reports from host countries that have received displaced Venezuelans may provide an improved understanding of the health needs of these migrants.

An emphasis on surveillance and reporting of communicable diseases by host countries, rather than NCDs and maternal and child health, has been observed across most countries receiving Venezuelan migrants. Thus, rates of NCDs such as hypertension, diabetes, cardiac disease, and cancers, are poorly described with resultant deprioritization and lower allocation of resources towards these high-burden conditions. A lack of a full epidemiologic picture of Venezuelan migrants complicates the preparedness of host countries and strategic usage of international aid.

The Venezuelan migration represents one of the largest modern day humanitarian crises with similar displacement in 2019 as compared to Syria in 2015. Despite the magnitude of this crisis, international aid has been limited. ${ }^{26}$ Thus, responses have fallen almost exclusively to neighboring host countries. In this study, a review of scientific publications and grey literature is presented to provide a broad contextual understanding of NCD and maternal and child health needs of Venezuelan migrants in the major South American host countries. We hypothesize that there is limited data on NCDs and maternal and child health needs in the Venezuelan migrant population across migrant countries. The findings of this analysis may be used by regional leaders, policy-makers, health care professionals, and humanitarian organizations to inform resource allocation and plan interventions to address NCDs in Venezuelan migrants. This review also highlights important gaps in current epidemiological knowledge of Venezuelan migrants that warrant further investigation and key areas for further research.

\section{METHODS}

\section{PEER-REVIEW SEARCH}

A systematic literature search was conducted following the Preferred Reporting Items for Systematic Reviews and Meta-Analyses (PRISMA) for Scoping Reviews guidelines to identify publications pertaining to Venezuelan migrants or refugees (Table 1). ${ }^{27}$ The electronic search strategy included the key words (Venezuela*) AND (displaced OR refugee* OR relocate* OR asylum OR migrant OR exodus OR crisis). Databases searched included: LILACS/ PAHO Virtual Health Library (BIREME), PubMed, SciELO, Global Health, Web of Science, Redalyc, Biblioteca Virtual en Desarrollo Sostenible y Salud, CINAHL, Cochrane, Embase, Global Index Medicus, Biomed Central. After removal of duplicates, titles and abstracts were screened by reviewers for inclusion using a conservative approach. Criteria for inclusion in this scoping review are listed in Table 1 . Publications primarily focused on infectious diseases were excluded as the focus of this review is on NCDs and maternal and child health. The search was limited to references published after 2016, 
Table 1: Study inclusion and exclusion criteria.

\begin{tabular}{|c|c|c|}
\hline Study characteristics & Inclusion criteria & Exclusion criteria \\
\hline Publication & Published after 2016 Manuscripts in English or Spanish & $\begin{array}{c}\text { Published before 2016 } \\
\text { Portuguese language due to } \\
\text { limitations in language skills of } \\
\text { screeners }\end{array}$ \\
\hline Participants & Venezuelan migrants from Colombia, Peru, Chile, Argentina, \\
Ecuador, Brazil & $\begin{array}{c}\text { Venezuelans residing within } \\
\text { Venezuela or a host country } \\
\text { with <100,000 Venezuelan } \\
\text { migrants in 2020 according to } \\
\text { the IOM } 28\end{array}$ \\
\hline Outcome measure & $\begin{array}{c}\text { *Prevalence and/or morbidity and mortality of NCDs including, } \\
\text { but not limited to, hypertension, cardiovascular health, diabetes, } \\
\text { psychiatric conditions *Prevalence and/or morbidity and mortality } \\
\text { of conditions related to maternal and child health }\end{array}$ & $\begin{array}{c}\text { Prevalence and/or morbidity } \\
\text { and mortality of communicable } \\
\text { diseases. }\end{array}$ \\
\hline Study design & $\begin{array}{c}\text { Primary Research (peer reviewed) or primary data reported (grey } \\
\text { literature) }\end{array}$ & $\begin{array}{c}\text { Secondary Research, including } \\
\text { Review articles, opinions, and } \\
\text { editorials }\end{array}$ \\
\hline
\end{tabular}

as this date corresponds to a rapid worsening of inflation in Venezuela and an efflux of migrants. ${ }^{28,29}$ The following South American countries with $>100,000$ Venezuelan migrants in 2020 according to the International Organization for Migration (IOM) were included for review: Argentina, Brazil, Chile, Colombia, Ecuador, and Peru. ${ }^{30}$ We suspect that the needs and responses of these receptor countries are varied. Therefore, data was grouped by country.

\section{GREY LITERATURE SEARCH}

To identify records from the grey literature, we searched the following databases: WHO Global Health Library, UN iLibrary (including UNHCR, UN University, UN Development Program, Inter-Agency Standing Committee, UNICEF), ReliefWeb, PAHO, Grey Literature Report in Public Health, Latin American Network Information Center (LANIC), International Committee of the Red Cross (ICRC), Doctors Without Borders International, Global Health Council, Center for Global Development, Research and Development (RAND) Corporation, Woodrow Wilson Center, Bill and Melinda Gates Foundation, Center for Global Health Research/University of Toronto, Center for Research on the Epidemiology of Disasters (CRED), International Rescue Committee, International Medical Corps, Oxfam International, Oxfam Great Britain, Deutsche Gesellschaft für Internationale Zusammenarbeit (GIZ), Center for Disease Control and Prevention (CDC), Humanitarian Practice Network, Ministries of Health of Colombia, Peru, Chile, Argentina, Ecuador, Brazil, World Bank, Confederación Médica de Latinoamérica y del Caribe (CONFEMEL), and Migration Policy Institute. The electronic search strategy for these sources varied across databases due to their functional differences, but otherwise the same key words as well as inclusion and exclusion criteria for the peer-review search above were used to select records.

\section{RESULTS}

The search yielded 1,098 records from 47 databases and other online sources, of which 972 (89.01\%) were found from peer-reviewed sources and 126 (11.5\%) from grey literature. A total of 1,081 records were excluded based on the following reasons: content not discussing Venezuelan migrants in Argentina, Brazil, Chile, Colombia, Ecuador, or Peru, (525), content not discussing NCDs (234), published before 2016 (320), or secondary research (2). For final analysis, 17 records were identified discussing Venezuelan migrant health. Two studies were from Argentina, ${ }^{31,32}$ two from Chile, 33,34 six from Colombia, ${ }^{35-40}$ and four from Peru. ${ }^{41-44}$ Three publications were based on regional evaluations including at least two countries. ${ }^{45-47}$ There were no records that satisfied our inclusion criteria for Brazil and Ecuador. Of note, there were no records removed based on the language exclusion criteria.

A total of 6 peer-reviewed records and 11 records from grey literature were included in this study (Figure 1). Peerreviewed publications included 1 abstract, 3 cross-sectional studies, and 2 observational retrospective studies. Grey literature publications included 1 cross-sectional study, 2 posters, and 8 reports. Most of the grey literature articles included were sponsored by international organizations such as the United Nations High Commissioner for Refugees (UNHCR) $(n=5)$, Save the Children $(n=2)$, Response for Venezuelans $(\mathrm{R} 4 \mathrm{~V})(\mathrm{n}=1)$, the Mixed Migration Center (MMC) $(n=1)$, and International Planned Parenthood Federation ( $n=1,9.1 \%)$. Additionally, there were also some studies within the grey literature authored by government sources such as the Instituto Nacional de Salud de Colombia $(n=1,9.1 \%)$. With respect to the year of publication, the greatest number of publications were from 2019 (10), followed by 2020 (5) and 2018 (2). There were no records published in 2017.

\section{ARGENTINA}

Two publications regarding Venezuelan migrants in Argentina were found in the grey literature describing general health characteristics of Venezuelan migrants. ${ }^{31,32}$ A 2019 UNHCR qualitative cohort study that interviewed 1,032 Venezuelan migrants revealed that $8.9 \%$ live with a critical 
Peer-Reviewed

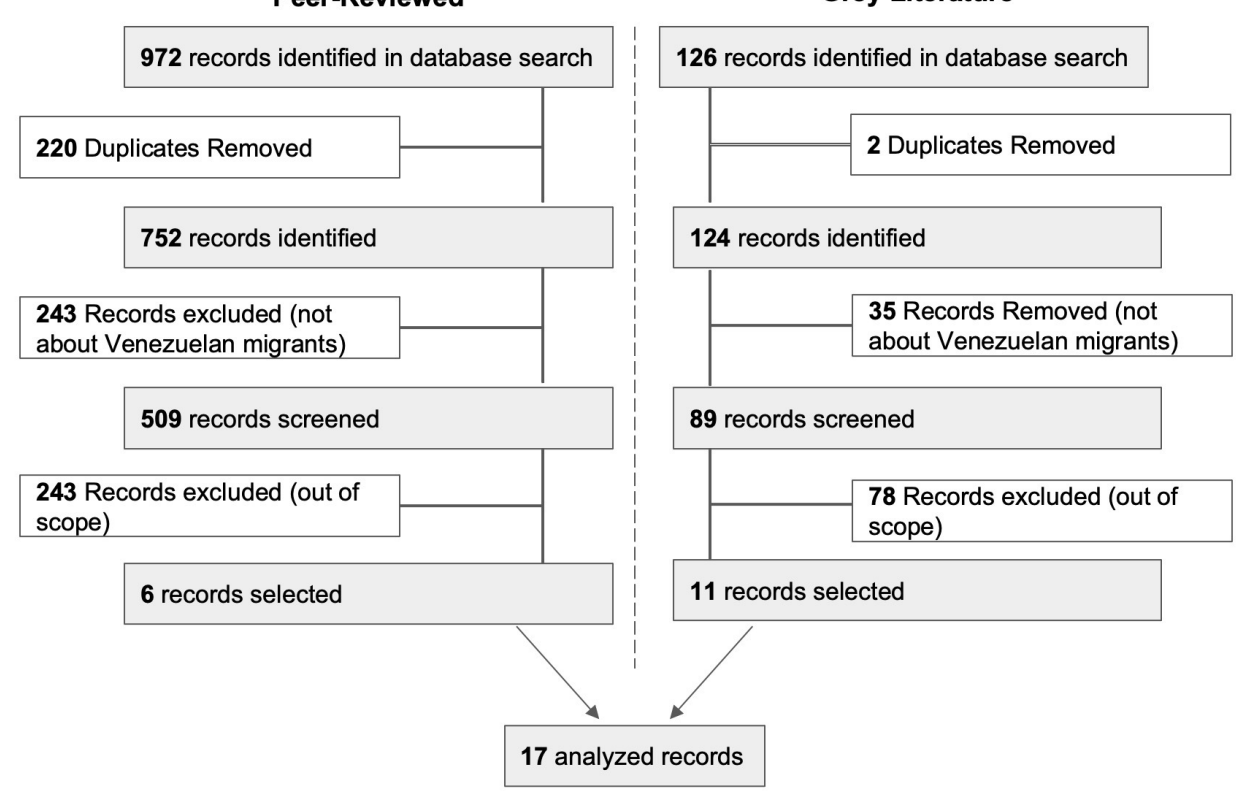

Figure 1: Flowchart of the record selection process for analysis.

chronic medical condition, with $31.1 \%$ of participants reporting health issues upon their arrival to Argentina and $94.7 \%$ seeking medical care. This study found that $9.0 \%$ of children in this analysis suffered from medical conditions. However, there was no discussion on the prevalence of specific NCD pathologies. Another 2019 qualitative study also conducted by UNHCR interviewed 504 Venezuelan migrants and noted that $13 \%$ of participants suffered from a mental or physical disability, with $31 \%$ of women confirming a chronic condition versus $13 \%$ of men. While this study noted that most of these medical problems were related to ophthalmologic conditions, there were no statistics reported and there was no discussion on what these pathologies were. ${ }^{32}$

\section{CHILE}

There were two publications regarding Venezuelan migrants in Chile. 33,34 One poster presented a cross-sectional study that assessed Venezuelan migrant children with Type 1 Diabetes Mellitus. ${ }^{33}$ This study evaluated hemoglobin A1c (HbA1c) levels - a marker of glycemic control - in 20 Venezuelan children upon establishing care in two public hospitals in Chile since 2010. There was an apparent decrease in H1Abc levels in their last medical visit compared to the most recent one considered $(p<0.05) .33$ The authors attributed this finding to improved knowledge on lifestyle management of type 1 diabetes mellitus as well as access to medications. A UNHCR report published in 2019 shows results from a study that 769 interviewed Venezuelan migrants. Of the interviewed individuals, $11 \%$ reported living with a disability, with the most common relating to vision $(\mathrm{n}=152)$ followed by physical disabilities $(\mathrm{n}=29)$ and hearing impairments $(n=14)$. A total of $11 \%$ of participants report having a chronic medical illness and $5 \%$ of children were found to have a medical condition, but no specific pathologies were discussed. ${ }^{34}$

\section{COLOMBIA}

A total of 4 records from the grey literature and 2 from peerreviewed sources were identified for Venezuelan migrants in Colombia, ${ }^{35-40}$ with most of these records focusing on chronic diseases and obstetric health.

A 2018 cross-sectional study that surveyed 175 Venezuelan migrants living in Villa Caracas in Barranquilla revealed that individuals self-reported suffering from chronic pain (30.7\%) followed by depression (19.8\%), hypertension (10.9\%), asthma (8.5\%), cough (7.9\%), and dyslipidemias $(7.2 \%) .{ }^{35} 4.2 \%$ of Venezuelan migrants reported cardiac pathologies and diabetes mellitus. None of the study participants reported suffering from cancer. Of note, $31.5 \%$ of Venezuelan migrants suffered from a medical emergency while living in Colombia. ${ }^{35}$ The reasons for seeking emergency care in this context were not discussed.

The Colombian Ministry of Health reported that the number of Venezuelan migrant births has increased from 5,561 in 2017 to 52,635 in $2019 .{ }^{36}$ There was no data explaining this trend. The most common obstetric conditions amongst Venezuelan migrants were related to amniotic cavity complications and compromised fetal health (41\%). Specific complications were not reported, however. Between 2017 and 2019, there has been a 215\% increase in maternal morbidity (26 reports versus 617 reports), a 132\% increase in perinatal mortality (28 reports versus 304 reports), and $138 \%$ rise in maternal mortality (5 reports versus 19 reports). ${ }^{48}$ The UNHCR has also reported a $76 \%$ rise in low birth weight amongst Venezuelan infants born in Colombia 
between 2017 and 2019 (7 reports versus 105). ${ }^{37}$ Another 2019 publication written by the International Planned Parenthood Federation and the organization of Profamilia reported that half of all maternal deaths in the Colombia (maternal mortality rate of 51 deaths for every 100,000 births) were among Venezuelan migrants. ${ }^{49}$ This report also found that Venezuelan migrants in Colombia are at risk for diabetes, hypertension, asthma, epilepsy, and psychiatric conditions, but there was no discussion on prevalence, morbidity, and mortality in this regard.

Similar to these findings, $61 \%$ of Venezuelan pregnant women that have sought care at Save the Children's Emergency Health Unit clinic on the Colombia-Venezuela border have presented with high-risk pregnancies and that over half of these women suffering from anemia linked to nutritional deficiencies. ${ }^{39}$ These statistics are consistent with 2019 study of Venezuelan migrants in the Caribbean region of Colombia, which found that $51.3 \%$ of pregnant women suffered from iron-deficiency anemia and $32.1 \%$ from depression. ${ }^{40}$

\section{PERU}

A total of four publications were identified from Peru. ${ }^{41-44}$ A 2020 qualitative study from Save the Children that interviewed 1,224 Venezuelan migrants living in Lima and Trujillo shows that $40 \%$ of these individuals were visually impaired, $16 \%$ had a memory or concentration impairment, and $17 \%$ had difficulty walking. ${ }^{41}$ A 2019 study that inspected data from the Encuesta sobre las Condiciones de Vida de la Población Venezolana que residen en Perú (ENPOVE) - which surveyed 3,611 households in Arequipa, Callao, Cusco, Lima, Trujillo, and Tumbes - revealed that $11 \%$ of Venezuelan migrants self-reported living with a chronic condition. ${ }^{43}$ Within this group, the most common complaints were asthma (39\%), hypertension (18.4\%), arthritis (4.8\%), diabetes $(4.6 \%)$, and malignancy $(2.1 \%)$. A total of $3.4 \%$ of women reported living with cancer, versus $0.5 \%$ of men. In addition, $44 \%$ of participants reported experiencing the onset of an illness upon arrival to Peru - mostly respiratory and gastrointestinal in nature. Only $2 \%$ reported living with a physical disability. Another 2019 cross-sectional study of 212 Venezuelan migrants living in the northern cities of Chimbote and Nuevo Chimbote that describes health-related quality of life (HRQoL) shows that more than two-thirds of the participants live with depression or anxiety (68.9\%). Other reported HRQoL dimensions included pain and discomfort (18.4\%), and issues with usual activities (2.4\%), mobility (1.4\%), and self-care (0.5\%). ${ }^{42}$

A cross-sectional study that included 16 Venezuelan migrants who received hemodialysis through the Peruvian Ministry of Health by July 2019 found a relatively low usage of hemodialysis and highlights that most of these patients were younger than $65 .{ }^{44}$ However this study did not comment on the specific prevalence of kidney pathologies amongst the Venezuelan migrant population.

\section{REGIONAL}

A total of three records discussing multiple countries in Latin America were included in this study; all were from grey literature ${ }^{45-47}$ A 2019 study led by the UNHCR interviewed 7,846 Venezuelan migrant families (totaling over 19,600 individuals) located in Argentina, Brazil, Chile, Colombia, Dominican Republic, Ecuador, Peru, and Uruguay. ${ }^{45}$ Within this population, 1,838 individuals reported suffering from critical or chronic medical conditions, 1,104 were pregnant or lactating women, 581 had disabilities, and 103 were older people at risk. ${ }^{45}$ Moreover, $25.8 \%$ of respondents mentioned they had a pre-existing health condition when migrating from Venezuela. ${ }^{45}$ Even though $91 \%$ of Venezuelan migrants in this study received some form of medical attention, obstacles cited to accessing care included lack of documentation, lack of health insurance, lack of information, and lack of resources to cover expenses. ${ }^{45}$ Other notable findings from this study were that $37 \%$ of migrants reported eating less than two meals per day and that $43 \%$ of migrants suffered from discrimination and limited access to housing, all of which can directly impact the longterm mental and physical health of this population. ${ }^{45}$

In addition to the UNHCR, a 2020 report from Response for Venezuelans (R4V) including Brazil, Chile, Colombia, Ecuador, Peru, the Caribbean, Central America, and Mexico provides additional insights into NCDs affecting Venezuelan migrants. ${ }^{46}$ For example, in Chile, gastrointestinal diseases, malignancy, and respiratory diseases were cited as common causes of hospital admissions for Venezuelan migrants, while diabetes, hypertension, malnutrition, and mental health disorders such as substance use disorders and post-traumatic stress disorder were cited as common chronic diseases affecting this population. ${ }^{46}$ In Mexico, $14 \%$ of Venezuelan migrants in the study were found to have one or more chronic diseases such as hypertension, hyperthyroidism, diabetes, thyroid disorders, and cancer, and 18\% required daily or regular medications. ${ }^{46}$ In Ecuador, 10\% of people surveyed suffered from chronic diseases and $72 \%$ mentioned experiencing stress from emotional distress during the year. ${ }^{46}$ In addition to the prevalence of NCDs in the Venezuelan migrant population, the report highlighted how migrants in Peru had limited access to healthcare given lack of coverage for chronic disease or mental health services. For instance, $71 \%$ of migrants were found to be in need of medical support and $78 \%$ of those with chronic illnesses were not receiving treatment. ${ }^{46}$ Venezuelan migrants in the Caribbean have also highlighted language barriers, lack of knowledge of services, lack of availability of services, and high cost as barriers to receiving care.

Lastly, a report by the Mixed Migration Centre in 2019 describing Venezuelan migrants in Colombia, Ecuador, and Peru found that patients with chronic illnesses living in Venezuela have increasingly left the country due to increased difficulty accessing necessary treatment and medications to manage their chronic illnesses. ${ }^{41}$ Additionally, the study found that a significant number of Venezuelan refugees had migrated to Colombia by foot under intense conditions, exposing them to dehydration, food exposure to extreme temperatures, food insecurity, and lack of access to sanitary products. This report also notes that Venezuelan migrants in Colombia with an undocumented migrant status did not have access to specialized medical care, therapies, and medicines limiting care for patients with chronic diseases. 


\section{DISCUSSION}

To the authors' knowledge, this is the first attempt to synthesize evidence from a broad range of global literature examining the burden of NCDs among Venezuelan migrants across South America. Notably, during the search process, it was observed that a majority of the literature concerning the health of Venezuelan migrants in South America has focused on infectious diseases. There is an alarming paucity of data concerning the epidemiology of NCDs amongst Venezuelan migrants in South American host countries. The lack of identified records solely focusing on health needs in Brazil and Ecuador highlights the extent of the scarcity of data as well as variations in data available by host country. Of note, there were no peer-reviewed records that were excluded solely on the basis of being written in Portuguese. While our study confirms that there is a substantial burden of NCDs in the Venezuelan migrant population across the region, there is a limited epidemiologic data regarding key information including: the prevalence of specific NCDs, morbidity and mortality associated with NCDs, and complications of NCDs. In addition, the lack of granularity concerning NCDs in the Venezuelan migrant populations represents a significant challenge for local health authorities and international humanitarian aid organizations to allocate resources and strategically support the healthcare needs of these groups.

A majority of the peer-reviewed literature published on this subject was written by local researchers, with the greatest number of studies being published in Colombia followed by Peru. Colombia was also the only country where the ministry of health had a record published that focused on NCDs. Thus, our results suggest that there is an urgent need for further research into NCD burdens of Venezuelan migrants, especially outside of Colombia.

NCDs represent a significant burden for Venezuelan migrants with a prevalence rate of chronic disease with reports ranging from $9-14 \%$. Specifically, NCDs were found in $8.9 \%$ of the Venezuelan population in Argentina, 10\% in Ecuador, $11 \%$ in Chile, and $14 \%$ in Mexico. $31,34,46$ The analysis also found common conditions experienced by migrants included mental health conditions such as depression and post-traumatic stress disorder, ophthalmologic conditions, diabetes, chronic pain, asthma, cough, dyslipidemia, hypertension, arthritis, and malnutrition. Obstacles to care cited included lack of health coverage, affordability, and lack of information. Lastly, maternal health, especially in Colombia, has been greatly affected in the Venezuelan migrant population as they face increases in maternal morbidity, perinatal mortality, and maternal mortality.

A notable theme in the included publications was the frequent report of vision problems among Venezuelan migrants in Argentina and Colombia, but none of these reports commented on specific pathologies. It is unclear, therefore, what ophthalmologic conditions are most prevalent and what specific medical and non-medical interventions are warranted in this regard. Maternal mortality was also a common theme, but granular data of specific pathologies was lacking.

There were also several reports that indicated that physical disabilities were a concern in this population, although similarly precise data on prevalence and diagnoses were not delineated in the included studies. Similarly, multiple items commented on a burden of mental health conditions in these migrant populations, but statistics on exact diagnoses were not provided.

A greater understanding of baseline needs in order to establish consistent access to healthcare resources that can support Venezuelan migrants living with NCDs are greatly needed. For many NCDs, poor adherence to care plans can lead to significant comorbidities or complications. For example, in diabetes mellitus, long term complications include diabetic retinopathy, heart disease, and chronic kidney disease while acute decompensation may lead to diabetic ketoacidosis. Untreated, these complications are more expensive and difficult to treat compared to establishing high-quality preventive and primary care for NCDs.

Identifying exact pathologies and describing their prevalence, morbidity, and mortality of chronic medical conditions, physical disabilities, ophthalmologic conditions, nutritional status, and obstetric complications as well as baseline cardiovascular and respiratory health will be valuable. Similarly, investigations should aim to describe the impact that relocation to host countries has had on the health of the Venezuelan migrant populations. Such analyses could further elucidate important barriers to care that may need to be addressed. Cross-sectional studies, conducted across the South American countries that have a high influx of Venezuelan migrants could serve as a useful tool to get a better understanding of the prevalence and distribution of NCDs in this population. We suspect that clarifying the epidemiologic profile of NCDs in the Venezuelan migrant population would ultimately enhance the efforts of host countries and the international community to adequately protect their health and wellbeing.

\section{CONCLUSIONS}

Based on this analysis, it can be concluded that there are important gaps in knowledge regarding specific pathologies of NCDs and maternal and child health amongst Venezuelan migrants in South American countries. While most records confirmed the presence of general health burdens on the migrant population, there was limited information on the prevalence, morbidity, and mortality of specific pathologies. In order to inform host countries about preparedness and disease prevention, efforts must be placed in fully describing the health status of Venezuelan migrants.f

\section{ACKNOWLEDGEMENTS}

None.

\section{FUNDING}

BGM was supported by NIH/NIAID R25AI140490. 
Table 2: Prevalence of non-communicable Diseases of Venezuelan migrants identified through this scoping review.

\begin{tabular}{|l|l|l|l|}
\hline $\begin{array}{l}\text { Noncommunicable } \\
\text { Disease }\end{array}$ & Prevalence & Number of References & Countries included \\
\hline $\begin{array}{l}\text { Chronic condition } \\
\text { (general) }\end{array}$ & $10-31 \%$ & $\begin{array}{l}11[31,32,34,35,40,43, \\
43,44,45,46,49]\end{array}$ & $\begin{array}{l}\text { Argentina, Colombia, Chile, Peru, } \\
\text { Regional }\end{array}$ \\
\hline Physical disability & $11-13 \%$ & $5[31,32,34,41,43]$ & Argentina, Chile, Peru, Regional \\
\hline Diabetes & $4.2-4.6 \%$ & $5[33,35,43,46,49]$ & Chile, Colombia, Peru, Regional \\
\hline Hypertension & $10.9-18.4 \%$ & $4[35,43,46,49]$ & Colombia, Peru, Regional \\
\hline $\begin{array}{l}\text { Mental health } \\
\text { (depression) }\end{array}$ & $68.9 \%$ & $7[32,35,40,42,45,46,49]$ & Argentina, Colombia, Peru, Regional \\
\hline Asthma & $8.5-39 \%$ & $3[35,43,49]$ & Colombia, Peru \\
\hline Malignancy & $2.1 \%$ & $2[43,46]$ & Peru, Regional \\
\hline
\end{tabular}

\section{AUTHORSHIP CONTRIBUTIONS}

KM conceptualized the idea for this project and designed the methodology. BGM, AA, GMP, and KM searched the literature. BGM, AA, and GMP analyzed findings and wrote the first draft of the manuscript. BGM, AA, GMP, SCG, KM, and ACL contributed equally to the editing and revisions of the manuscript.

\section{COMPETING INTERESTS}

The authors completed the Unified Competing Interest form at www.icmje.org/coi_disclosure.pdf (available upon request from the corresponding author), and declare no conflicts of interest.

Submitted: April 07, 2021 GMT, Accepted: May 01, 2021 GMT 


\section{REFERENCES}

1. United Nations High Commissioner for Refugees. Venezuela Situation. Accessed February 25, 2021. http s://www.unhcr.org/en-us/venezuela-emergency.html

2. Chaves-González D, Echevarría Estrada C. Venezuelan migrants and refugees in Latin America and the Caribbean: A regional profile. Published September 7, 2020. Accessed February 25, 2021. http s://repositoryoim.org/handle/20.500.11788/2308

3. Wickramage K, Vearey J, Zwi AB, Robinson C, Knipper M. Migration and health: a global public health research priority. BMC Public Health. 2018;18(1):987. doi:10.1186/s12889-018-5932-5

4. Villalba JA. The challenges of restructuring health care in Venezuela. Lancet. 2018;392(10144):278-279. doi:10.1016/s0140-6736(18)31384-9

5. Mendoza C, Urbina JA. Venezuelan researchers call for international help. Nature.

2003;421(6922):473-473. doi:10.1038/421473a

6. Verhagen LM, Warris A, Hermans PWM, del Nogal B, de Groot R, de Waard JH. High Prevalence of Acute Respiratory Tract Infections Among Warao Amerindian Children in Venezuela in Relation to Low Immunization Coverage and Chronic Malnutrition. Pediatric Infectious Disease Journal. 2012;31(3):255-262. doi:10.1097/inf.0b013e31823eed $\underline{8 \mathrm{e}}$

7. Fraser B. Science under siege: how Venezuela's economic crisis is affecting researchers. Nature. 2016;535(7612):336-337. doi:10.1038/nature.2016.20 $\underline{261}$

8. Requena J. Venezuela's brain drain is accelerating. Nature. 2016;536(7617):396-396. doi:10.1038/536396 $\underline{\mathrm{d}}$

9. Fraser B, Willer H. Venezuela: aid needed to ease health crisis. Lancet. 2016;388(10048):947-949. doi:1 $\underline{0.1016 / \mathrm{s} 0140-6736(16) 31523-9}$

10. The Lancet. Venezuelans' right to health crumbles amid political crisis. Lancet. 2019;393(10177):1177. do i:10.1016/s0140-6736(19)30729-9

11. Roa AC. Sistema de salud en Venezuela: ¿un paciente sin remedio? Cad Saúde Pública. 2018;34(3). doi:10.1590/0102-311x00058517
12. Venezuela's Humanitarian Crisis. Published October 24, 2016. Accessed March 29, 2021. https://w ww.hrw.org/report/2016/10/24/venezuelas-humanitar ian-crisis/severe-medical-and-food-shortages-inadeq uate-and

13. Raphelson S. Venezuela's Health Care System Ready To Collapse Amid Economic Crisis. NPR. Published online February 1, 2018. Accessed March 28, 2021. https://www.npr.org/2018/02/01/58246930 5/venezuelas-health-care-system-ready-to-collapseamid-economic-crisis

14. Daryanani S. When populism takes over the delivery of health care: Venezuela.

Ecancermedicalscience. 2017;11. doi:10.3332/ecancer.2 $\underline{017 . e d 73}$

15. Friedrich MJ. Venezuela's Infant Death Rate Rises Amid Worsening Humanitarian Crisis. JAMA. 2019;321(11):1041. doi:10.1001/jama.2019.1933

16. Doocy S, Ververs MT, Spiegel P, Beyrer C. The food security and nutrition crisis in Venezuela. Soc Sci Med. 2019;226:63-68. doi:10.1016/j.socscimed.2019.0 $\underline{2.007}$

17. Page KR, Doocy S, Reyna Ganteaume F, Castro JS, Spiegel P, Beyrer C. Venezuela's public health crisis: a regional emergency. Lancet. 2019;393(10177):1254-1260. doi:10.1016/s0140-673 $\underline{6(19) 30344-7}$

18. García J, Correa G, Rousset B. Trends in infant mortality in Venezuela between 1985 and 2016: a systematic analysis of demographic data. Lancet Glob Health. 2019;7(3):e331-e336. doi:10.1016/s2214-109 $\underline{\mathrm{x}(18) 30479-0}$

19. Food and Agriculture Organization of the United Nations, United Nations International Children's Emergency Fund, World Health Organization, World Food Programme, International Fund for Agriculture Development. In: The State of Food Security and Nutrition in the World 2018: Building Climate Resilience for Food Security and Nutrition. Food \& Agriculture Org. ; 2018. https://play.google.com/store/books/deta ils?id=LC9uDwAAOBAI

20. The Lancet. Venezuelans' right to health crumbles amid political crisis. Lancet. 2019;393(10177):1177. do $\underline{\mathrm{i}: 10.1016 / \mathrm{s} 0140-6736(19) 30729-9}$ 
21. Zoghbi N, López Á. La llegada del virus zika a venezuela y su posible huella en la salud maternainfantil. una discusión impostergable. Comunidad y Salud. 2016;14(1):67-73. http://ve.scielo.org/scielo.ph p?script=sci_arttext \&pid $=$ S1690-32932016000100010

22. Grillet ME, Hernández-Villena JV, Llewellyn MS, et al. Venezuela's humanitarian crisis, resurgence of vector-borne diseases, and implications for spillover in the region. Lancet Infect Dis. 2019;19(5):e149-e161. doi:10.1016/s1473-3099(18)30757-6

23. Claborn DM. A Narrative Review of the Role of Economic Crisis on Health and Healthcare Infrastructure in Three Disparate National Environments. Int J Environ Res Public Health. 2020;17(4). doi:10.3390/ijerph17041252

24. World Health Organization. Global Status Report on Noncommunicable Diseases 2010. World Health Organization. Published online 2011. https://play.goo gle.com/store/books/details?id=SRRKKQEACAAJ

25. Paniz-Mondolfi AE, Sordillo EM, MárquezColmenarez MC, Delgado-Noguera LA, RodriguezMorales AJ. The arrival of SARS-CoV-2 in Venezuela. Lancet. 2020;395(10236):e85-e86. doi:10.1016/s014 $\underline{0-6736(20) 31053-9}$

26. Bahar D, Dooley M. Venezuela refugee crisis to become the largest and most underfunded in modern history. Brookings. Published online December 9, 2019. Accessed March 28, 2021. https://www.brooking s.edu/blog/up-front/2019/12/09/venezuela-refugee-cr isis-to-become-the-largest-and-most-underfunded-i n-modern-history/

27. Hoque R, Strotheide E, Saquib J, Saquib N. Assessment of nationally representative dietary studies in the Gulf Cooperation Council: a scoping review. PeerJ. 2020;8:e10163. doi:10.7717/peerj.10163

28. Venezuela 2016 inflation hits 800 percent, GDP shrinks 19 percent: document. Reuters. Published January 20, 2017. Accessed March 15, 2021. https://w ww.reuters.com/article/us-venezuela-economy-idUSK BN154244.

29. Migration trends in the Americas: Bolivarian republic of Venezuela. Published April 2018. Accessed March 15, 2021. https://reliefweb.int/report/colombi a/migration-trends-americas-bolivarian-republic-ven ezuela-april-2018

30. Situation Response for Venezuelans. Accessed March 29, 2021. https://r4v.info/en/situations/platfor $\underline{m}$
31. UNHCR protection monitoring dashboard Argentina. Published February 2019. Accessed February 21, 2021. https://data2.unhcr.org/en/docum ents/details/68729

32. Aspectos claves Monitoreo de Protección Venezolanos en Argentina - Julio - Diciembre 2019. Accessed February 21, 2021. https://data2.unhcr.org/e n/documents/details/73775

33. Poster Tours and Posters on Display. Pediatr Diabetes. 2019;20(S28):41-231. doi:10.1111/pedi.1292 $\underline{4}$

34. Monitoreo de Protección en Chile. Published 2019. Accessed February 24, 2021. https://data2.unhc r.org/en/documents/details/73955

35. Portal de Revistas UN. Accessed February 4, 2021. http://mr.crossref.org/iPage?doi=10.15446\%2Frsap.v2 0n4.75773

36. Colombia: Situación de la Salud Sexual y Reproductiva de la Población Migrante y Refugiada de Venezuela. Accessed February 25, 2021. https://data 2.unhcr.org/en/documents/details/75496

37. Ministerio de Salud Colombia: Población venezolana en Colombia. Published May 2019. Accessed February 25, 2021. https://data2.unhcr.org/e $\underline{\mathrm{n} / \text { documents/details/70238 }}$

38. Evaluación de las necesidades insatisfechas en salud sexual y salud reproductiva de la población migrante venezolana en cuatro ciudades de la frontera colombo-venezolana - Colombia. Accessed February 25, 2021. https://reliefweb.int/report/colom bia/evaluaci-n-de-las-necesidades-insatisfechas-en-s alud-sexual-y-salud-reproductiva-de

39. Save the Children International. Hundreds of heavily pregnant Venezuelan women seek treatment at Save the Children Colombian border clinic.

Published July 10, 2019. Accessed March 4, 2021. http s://www.savethechildren.net/news/hundreds-heavilypregnant-venezuelan-women-seek-treatment-save-c hildren-colombian-border-clinic

40. Fernández-Niño JA, Rojas-Botero ML. Health situation of Venezuelan pregnant migrants in the Colombian Caribbean: first report for a rapid response in Public Health. Revista de la. Published online 2019. http://www.scielo.org.co/scielo.php?pid=S0121-0807 $2019000300208 \&$ script $=$ sci arttext \&tlng $=$ en

41. Health needs in Lima and Trujillo, Peru. Published March 2020. Accessed March 4, 2021. https://reliefwe b.int/report/peru/health-needs-lima-and-trujillo-per u-march-2020 
42. Figueroa-Quiñones J, Cjuno J, Ipanaqué-Neyra J, Ipanaqué-Zapata $\mathrm{M}$, Taype-Rondan A. Calidad de vida de migrantes venezolanos en dos ciudades del norte del Perú. Rev Peru Med Exp Salud Publica. 2019;36(3):383-391. doi:10.17843/rpmesp.2019.363.4 $\underline{517}$

43. Mendoza W, Miranda JJ. La inmigración venezolana en el Perú: desafíos y oportunidades desde la perspectiva de la salud. Rev Peru Med Exp Salud Publica. 2019;36(3):497-503. doi:10.17843/rpme sp.2019.363.4729

44. Benites-Zapata VA, Herrera-Añazco P, YarascaZegarra C, Venegas-Ojeda D, Flores-Benites V. Inmigrantes venezolanos en hemodiálisis atendidos en el Ministerio de Salud de Perú. Rev Peru Med Exp Salud Publica. 2020;36(4):709-710. doi:10.17843/rpme sp.2019.364.4712

45. Protection Monitoring. Accessed March 5, 2021. h ttps://data2.unhcr.org/en/documents/details/70440
46. RMRP 2020 - regional refugee and migrant response plan for refugees and migrants from Venezuela (January - December 2020) - Colombia. Published 2020. Accessed March 5, 2021. https://relief web.int/report/colombia/rmrp-2020-regional-refuge e-and-migrant-response-plan-refugees-and-migrant s-venezuela

47. Waning welcome. Published September 4, 2019. Accessed March 5, 2021. https://mixedmigration.org/r esource/waning-welcome-the-growing-challenges-fa cing-mixed-migration-flows-from-venezuela/

48. Colombia: Situación de la Salud Sexual y Reproductiva de la Población Migrante y Refugiada de Venezuela. Accessed March 4, 2021. http://data2.unhc r.org/en/documents/details/75496

49. Evaluación de las necesidades insatisfechas en salud sexual y salud reproductiva de la población migrante venezolana en cuatro ciudades de la frontera colombo-venezolana - Colombia. Accessed March 4, 2021. https://reliefweb.int/report/colombia/ evaluaci-n-de-las-necesidades-insatisfechas-en-salu d-sexual-y-salud-reproductiva-de 